Original Article

\title{
THE EFFECTS OF OLIVE LEAF EXTRACT OINTMENT ON PAIN INTENSITY AND EARLY MATERNAL COMPLICATIONS IN PRIMIPAROUS WOMEN
}

\author{
MAASUMEH KAVIANI ${ }^{1}$, SARA SEPASI ${ }^{2}$, SARA AZIMA ${ }^{1}$, MASOUMEH EMAMGHOREISHI ${ }^{3}$, NASRIN ASADI ${ }^{4}$, \\ SEZANEH HAGHPANAH ${ }^{5}$
}

\begin{abstract}
1Department of Midwifery, School of Nursing and Midwifery, Shiraz University of Medical Sciences, Shiraz, Iran, ${ }^{2}$ Student Research Committee, Shiraz University of Medical Sciences, Shiraz, Iran, ${ }^{3}$ Maternal-fetal Medicine Research Center, Shiraz University of Medical Science, Shiraz Iran, ${ }^{4}$ Department of Pharmacology, School of Medicine, Shiraz University of Medical Sciences, Shiraz Iran, ${ }^{5}$ Department of Biostatistics and Hematology Research Center, Shiraz University of Medical Sciences, Shiraz, Iran
\end{abstract} Email: azimas@sums.ac.ir

Received: 26 Sep 2016 Revised and Accepted: 19 May 2017

\section{ABSTRACT}

Objective: This study aimed to assess the impact of olive leaf extract ointment on pain intensity and early maternal complications in primiparous women.

Methods: This randomized clinical trial was conducted on 90 primiparous women. The participants were randomly divided into three groups each containing 30 women. Groups A, B, and C used olive leaf extract ointment, placebo ointment, and betadine solution at the episiotomy area three times a day for $10 \mathrm{~d}$. Improvement of the episiotomy wound was evaluated using REEDA scale, and pain intensity were assessed through Visual Analogue Scale (VAS). The evaluations were performed $4 \mathrm{~h}$ and 3, 7, 10, and $14 \mathrm{~d}$ after delivery.

Results: The results showed a significant difference between the olive leaf extract ointment group and the other groups regarding the improvement of episiotomy wound $(\mathrm{p}<0.001)$. Pain intensity also significantly was reduced in this groups $10 \mathrm{~d}$ after delivery $(\mathrm{p}=0.029)$.

Conclusion: Olive leaf extract ointment was relatively effective in reduction of pain intensity and early maternal complications resulting from an episiotomy.

Keywords: Olive leaf, Pain, Episiotomy, Primiparous women

(C) 2017 The Authors. Published by Innovare Academic Sciences Pvt Ltd. This is an open access article under the CC BY license (http://creativecommons.org/licenses/by/4.0/) DOI: http://dx.doi.org/10.22159/ijpps.2017v9i7.15387

\section{INTRODUCTION}

Episiotomy refers to incision of the perineum during the second stage of delivery to spread the pelvic outlet and to prevent delay in fetal head delivery. Nowadays, episiotomy is not a popular method in developed countries but is routinely used in Asian countries where women have short perineum and strong tissues [1-5]. Episiotomy has some complications, including perineal pain and discomfort, bleeding, infection, damage to anal sphincter and mucosa, wound opening, rupture expansion, difficulty in sitting and holding one's infant, disruption of maternal-infantile relationships, and reduction of sexual desire. Therefore, wound healing is of particular importance [3, 6-7].

Various measures can be taken to reduce perineal pain and improve wound healing, including medications, warm and cold compresses, and use of infrared lamps. Complementary medicine, such as plants, homoeopathy, and aromatherapy, could also be used to reduce pain and heal episiotomy wound site [1-5].

Olea europaea L. contains oleuropein. This compound, together with other phenolic compounds in the olive leaf extract such as tyrosol, hydroxytyrosol, and oleanolic acid, possesses antimicrobial and antioxidant activities [8-10]. Thus, it is an appropriate candidate for wound healing [3].

Modern midwifery has put an emphasis on application of noninvasive therapeutic methods and herbal supplements accepted by people. Nonetheless, no study has been conducted on the effect of olive leaf extract ointment on pain intensity and early maternal complications. Thus, the present study aims to evaluate the impact of olive leaf extract ointment on pain intensity and early maternal complications in primiparous women.

\section{MATERIALS AND METHODS}

This randomized interventional clinical trial was conducted on 90 primiparous women in the selected hospitals of Shiraz University of Medical Sciences from the beginning of October to the end of
December 2015. Based on the study by Azhari et al. [3], considering $\alpha=0.05$ and power of $95 \%$, and using the following formula, a 75 subject sample size was determined for the study.

$$
\mathrm{N}=2(\mathrm{z} 1-\mathrm{a} / 2+\mathrm{z} 1-\beta)^{2} \tilde{\mathrm{o}}^{2} /(\mu 2-\mu 1)^{2}
$$

Considering the probable loss rate of $20 \%, 90$ participants were enrolled into this study (30 subjects in each group). Groups A, B, and C received olive leaf extract ointment (Oleaceae species, variety: Sevillano), placebo, and betadine diluted solution, respectively. The ingredients used in this study were olive leaf extract ointment $2 \%$ (Each $100 \mathrm{gr}$ of the ointment contains $2 \%$ olive leaf extract and $0.45 \%$ oleuropein active ingredient). For preparing olive leaf extract olive leaves were dried in the shade, then $1.00 \mathrm{~g}$ milled sample was transferred to a glass bottle and $10 \mathrm{ml}$ ethanol-water was added as the extraction solvent. The bottle was capped and sonicated for $15 \mathrm{~min}$ in an ultrasonic water bath at $40^{\circ} \mathrm{C}$. The mixture was then centrifuged at $4000 \mathrm{rpm}$ for $3 \mathrm{~min}$. The upper solution was decanted into a clean bottle and the extraction procedure was repeated on the sediment. The two extracts were combined, filtered through a $0.45-\mu \mathrm{m}$ membrane filter and stored at $4{ }^{\circ} \mathrm{C}$ until analysis. Placebo containing eucerin (made by Dana Kasaian Company, Khoramabad, Iran), and betadine solution (povidone iodine 10\%, Behvazan Pharmaceutical Company, Rasht, Iran). The participants were selected through simple random sampling. Then, they were divided into three groups through permuted block randomization as follows: $\mathrm{ABC}, \mathrm{ACB}, \mathrm{CAB}, \mathrm{CBA}, \mathrm{BAC}$, and BCA. This was done using the table of random numbers and numbers 0,7 , and 9 were excluded from the study.

The inclusion criteria of this study were being willing to cooperate, being 17-35 y old, being primiparous, gestational age of 37-42 w, singleton pregnancy, cephalic presentation, natural vaginal delivery with mediolateral episiotomy, Body Mass Index $(\mathrm{BMI})<30 \mathrm{~kg} / \mathrm{m}^{2}$, not having any history of reconstructive vaginal and perineal surgery, not using wound healing medications, and not suffering from specific diseases such as anemia, cardiovascular disorders, diabetes, immune disorders, liver disease, depression, coagulation 
disorders, preeclampsia, and infectious diseases. On the other hand, the exclusion criteria of this study were abnormal vaginal bleeding after delivery, postpartum fever and shivering, episiotomy area infection, need for resuturing, allergic reactions to the medication or the placebo, and unwillingness to participate in the study.

The study data were collected using a demographic information form, Visual Analogue Scale (VAS), and REEDA scale. REEDA scale contains five criteria, namely redness, edema, ecchymosis, discharge, and approximation of the wound edges, each receiving a score between 0 and 3 . Thus, the total score could range from 0 to 15, with lower scores representing better-wound healing [3]. REEDA is a standard scale with confirmed reliability and validity [11].

VAS is a ruler numerated from 0 to 10 , representing no pain and the highest pain intensity, respectively [12]. In order to determine the reliability of this instrument, Pazandeh used inter-rater assessment and reported Spearman's correlation coefficient as $r=0.95$ [13].

All the subjects underwent mediolateral episiotomy and the incisions were repaired by an expert midwife. Perineal repair and pain were evaluated $4 \mathrm{~h}$ and $3,7,10$, and $14 \mathrm{~d}$ after delivery. In each visit, pain intensity, redness, edema, ecchymosis, discharge, and approximation of the wound edges were evaluated. It should be noted that REEDA scale and VAS were completed by an assistant midwife to avoid bias. In addition, the three groups were equally trained regarding episiotomy wound care. In the case of need for analgesics, the mefenamic acid capsule was prescribed.

At first, the participants were required to rub some of the ointment on their inner forearm skins. In the case of any allergic reactions, the participants were excluded from the study. Then, the participants in groups A and B were asked to rub 1gr of the ointments on the suture area every $8 \mathrm{~h}$ for $10 \mathrm{~d}$ after delivery. Group C participants were also asked to take a sitz bath in 3 spoons of betadine solved in 4 glasses of water three times a day for $10 \mathrm{~d}$ after delivery. Since blinding was not possible, sampling was conducted on separate days. In case the subjects did not refer on the appointed dates, they were replaced by new cases. After all, 90 participants completed the study.

\section{Statistical analysis}

The study data were analyzed using chi-square test, ANOVA, Kruskal-Wallis, Mann-Whitney, Bonferroni, Wilcoxon, Friedman, and repeated measures ANOVA. All the analyses were performed using the SPSS statistical software (version 21) and $p<0.05$ was considered to be statistically significant.

\section{Ethical considerations}

This study was approved by the Ethics Committee of Shiraz University of Medical Sciences and was registered in the Iranian Registry of Clinical Trials (IRCT2015062422908N1). Besides, written informed consents were obtained from all the participants prior to the study.

\section{RESULTS}

This study was conducted on 90 primiparous women who had referred to the delivery wards of the hospitals affiliated to Shiraz University of Medical Sciences, Shiraz, Iran. The results revealed no significant differences among the three groups regarding demographic features, such as age, education level, occupation, and economic status, gestational age, BMI, durations of first, second, and third stages of delivery, number of skin surface sutures, length of episiotomy, infants' head circumference and weight, and need for analgesics.

The results also showed no significant difference among the three groups regarding wound redness. However, a significant difference was observed among the three groups in this regard on the $3^{\text {rd }}$ day postpartum $(\mathrm{p}=0.019)$ (table 1). The results of Mann-Whitney test (post-hoc) indicated that olive leaf extract and betadine groups were significantly different $(p=0.005)$. The results of Friedman test also showed that the trend of changes in the mean score of wound redness was significantly different in the three groups over time $(\mathrm{p}<0.001)$. The mean score of postpartum edema was also lower in the olive leaf extract ointment group compared to the other groups (table 1). Additionally, a significant difference was observed among the three groups concerning approximation of the wound edges 7 , 10 , and $14 \mathrm{~d}$ after delivery (table 1 ). In this regard, the results of Mann-Whitney test (post-hoc) indicated significant differences between the olive leaf extract and placebo groups on days 10 and 14 postpartum $(\mathrm{p}<0.001)$ as well as between olive leaf extract and betadine groups on days $7(\mathrm{p}=0.002), 10(\mathrm{p}<0.001)$, and 14 $(p<0.001)$ after delivery. Nonetheless, no significant difference was observed among the three groups with respect to the mean scores of ecchymosis and discharge (table 1).

Table 1: Comparison of the three groups regarding the scores of five REEDA scale variables

\begin{tabular}{|c|c|c|c|c|c|}
\hline Variables & Days after delivery & Olive leaf extract group ${ }^{a}$ & Placebo group ${ }^{a}$ & Betadine solution group ${ }^{a}$ & P-value \\
\hline \multirow[t]{5}{*}{ edness } & 1 & $2 \pm 0$ & $2.03 \pm 0.18$ & $2.03 \pm 0.18$ & $* 0.603$ \\
\hline & 3 & $0.2 \pm 0.4$ & $0.6 \pm 0.77$ & $0.63 \pm 0.66$ & $* 0.019$ \\
\hline & 7 & $0.07 \pm 0.25$ & $0.27 \pm 0.52$ & $0.43 \pm 0.81$ & $* 0.090$ \\
\hline & 10 & $0.03 \pm 0.18$ & $0.13 \pm 0.34$ & $0.2 \pm 0.48$ & $* 0.229$ \\
\hline & 14 & 0 & 0 & $0.1 \pm 0.4$ & *0.132 \\
\hline \multirow[t]{5}{*}{ Edema } & 1 & $1 \pm 0$ & $1.03 \pm 0.18$ & $1.03 \pm 0.18$ & $* 0.603$ \\
\hline & 3 & $0.67 \pm 0.47$ & $0.83 \pm 0.37$ & $0.97 \pm 0.49$ & $* 0.051$ \\
\hline & 7 & $0.2 \pm 0.4$ & $0.43 \pm 0.56$ & $0.47 \pm 0.57$ & $* 0.111$ \\
\hline & 10 & $0.07 \pm 0.25$ & $0.2 \pm 0.4$ & $0.2 \pm 0.4$ & $* 0.262$ \\
\hline & 14 & 0 & $0.03 \pm 0.18$ & $0.07 \pm 0.25$ & $* 0.360$ \\
\hline \multirow[t]{5}{*}{ Ecchymosis } & 1 & 0 & $0.17 \pm 0.64$ & $0.2 \pm 0.76$ & ** 0.973 \\
\hline & 3 & 0 & $0.17 \pm 0.64$ & $0.17 \pm 0.64$ & $* *>0.999$ \\
\hline & 7 & 0 & 0 & 0 & - \\
\hline & 10 & 0 & 0 & 0 & - \\
\hline & 14 & 0 & 0 & 0 & - \\
\hline \multirow[t]{5}{*}{ Discharge } & 1 & 0 & 0 & 0 & - \\
\hline & 3 & 0 & 0 & 0 & - \\
\hline & 7 & 0 & 0 & 0 & - \\
\hline & 10 & 0 & 0 & 0 & - \\
\hline & 14 & 0 & 0 & 0 & - \\
\hline \multirow[t]{5}{*}{ Approximation of wound edges } & 1 & 0 & 0 & 0 & - \\
\hline & 3 & $0.07 \pm 0.25$ & $0.2 \pm 0.4$ & $0.27 \pm 0.45$ & * 0.122 \\
\hline & 7 & $0.37 \pm 0.49$ & $0.6 \pm 0.67$ & $0.87 \pm 0.62$ & $* 0.009$ \\
\hline & 10 & $0.13 \pm 0.34$ & $0.67 \pm 0.66$ & $0.9 \pm 0.75$ & $*<0.001$ \\
\hline & 14 & 0 & $0.4 \pm 0.49$ & $0.47 \pm 0.57$ & $*_{<}<0.001$ \\
\hline
\end{tabular}

amean+SD, n=30. *Kruskal-Wallis, **Mann-Whitney. 
Moreover, the results of Mann-Whitney test (posthoc) demonstrated a significant difference between the olive leaf extract ointment and placebo groups regarding the total score of REEDA scale on days $3(p=0.009), 7(p=0.013), 10(p<0.001)$, and $14(\mathrm{p}<0.001)$ after delivery. A significant difference was also observed between the olive leaf extract ointment and betadine groups in this regardon days $3,7,10$, and 14 postpartum $(\mathrm{p}<0.001)$ (table 2).

Table 2: Comparison of the three groups regarding the total score of REEDA scale

\begin{tabular}{llllll}
\hline Variable & Days after delivery & Olive leaf extract group & Placebo group & Betadine solution group $^{\mathbf{a}}$ & P-value Kruskal-Wallis $^{\text {P }}$ \\
\hline Total score of & 1 & $3 \pm 0$ & $3.23 \pm 0.72$ & $3.27 \pm 0.78$ \\
REEDA scale & 3 & $0.93 \pm 0.64$ & $1.8 \pm 1.34$ & $2.03 \pm 1.37$ \\
& 7 & $0.63 \pm 0.85$ & $1.3 \pm 1.08$ & $1.77 \pm 1.25$ \\
& 10 & $0.23 \pm 0.5$ & $1 \pm 0.94$ & $1.3 \pm 1.17$ \\
& 14 & 0 & $0.43 \pm 0.56$ & $0.63 \pm 0.76$ & $<0.001$ \\
\hline
\end{tabular}

amean+SD, $n=30$.

Considering the mean score of pain intensity, a significant difference was observed among the three groups on the $10^{\text {th }}$ day after delivery $(p=0.029)$. Besides, the results of Bonferroni test indicated that this difference was between olive leaf extract and betadine groups (table 3). Yet, the three groups were similar with respect to the amount of consumed analgesics.

Table 3: Comparison of the three groups regarding the mean score of episiotomy pain intensity

\begin{tabular}{|c|c|c|c|c|c|}
\hline Variable & Days after delivery & Olive leaf extract group ${ }^{a}$ & Placebo group $^{a}$ & Betadine solution group $^{a}$ & P-value ANOVA \\
\hline Mean score of & 1 & $4.30 \pm 2.74$ & $5.1 \pm 2.85$ & $5.97 \pm 2.69$ & 0.071 \\
\hline episiotomy pain & 3 & $3.8 \pm 2.18$ & $3.97 \pm 2.67$ & $4.17 \pm 2.46$ & 0.845 \\
\hline \multirow[t]{3}{*}{ intensity } & 7 & $2.23 \pm 1.85$ & $3.4 \pm 2.79$ & $3.67 \pm 2.59$ & 0.060 \\
\hline & 10 & $0.83 \pm 1.28$ & $1.83 \pm 2.08$ & $1.97 \pm 1.82$ & 0.029 \\
\hline & 14 & $0.13 \pm 0.34$ & $0.57 \pm 1.33$ & $0.67 \pm 0.92$ & 0.077 \\
\hline
\end{tabular}

amean+SD, $\mathrm{n}=30$.

\section{DISCUSSION}

This study aimed to assess the effect of olive leaf extract ointment on early maternal complications in primiparous women. The results revealed significantly lower redness at the episiotomy area in the olive leaf extract group compared to the betadine group three days postpartum. However, no significant difference was observed among the three groups in this regard four hours after delivery, which might be due to non-presence of inflammatory and allergic reactions leading to redness of the wound. Also, no significant difference was observed among the three groups in this regard on days 7,10 , and 14 postpartum, which might be attributed to the natural process of wound healing and elimination of redness that caused the effect of olive not to be noticeable anymore.

The study results revealed no significant difference among the three groups concerning the mean score of edema before and after the intervention. However, olive leaf extract ointment was effective in reduction of the distance between the episiotomy wound edges. Similarly, Behmanesh et al. (2013) compared the effects of sitz bath in olive oil and distilled water on the improvement of perineal injury after delivery and reported lower redness in the olive oil group on the $5^{\text {th }}$ day [14].

Vakilian et al. (2007) also conducted a study to assess the impact of the lavender extract on the improvement of episiotomy wound. In that study, lavender essential oil was prepared through distillation with olive oil carrier. The results indicated that the mean of episiotomy wound redness was lower in the lavender group compared to the betadine group on the $5^{\text {th }}$ day [15].

The results of the two above-mentioned studies were in agreement with those of the current one. Olive leaf extract contains a large volume of oleuropein (the main phenolic compound of olive leaf) and other phenolic compounds, such as tyrosol, hydroxytyrosol, and oleanolic acid, with antimicrobial and antioxidant properties [7, 16-7] that are effective in repairing damaged tissues and healing of skin wounds [8-10, 18]. This was also confirmed in the research by Koka et al. (2011) whose results were consistent with those of the present study [19].

Furthermore, Yu et al. (2008) reported vitamin C as one of the effective factors in skin wounds healing [20]. In the same line, Jagetia et al. (2004) disclosed that vitamin $\mathrm{C}$ increased collagen content and vascular density in skin wounds [21]. Hence, large amounts of vitamin $\mathrm{C}$ in the compounds isolated from the olive fruit and leaf extracts could quicken skin wounds healing [22]. Mehraein et al. (2014), too, performed a study on 24 male rats and reported that oleuropein quickened the healing of skin wounds [23].

Generally, one of the important factors in wound healing is the prevention of edema in the area. Suntar et al. (2010) referred to the anti-inflammatory effects of olive [24]. Similarly, Cvjeticanin et al. (2010) stated that olive leaf extract avoided the effects of inflammatory compounds, such as cytokines, IFN- $\gamma$, IL-12, and IL-17 [25]. In contrast to the current study, Behmanesh et al. (2013) revealed a significant difference between the study groups regarding edema only on day 10 postpartum [14]. The results of the study by Vakilian et al. (2007) also showed that edema was significantly higher in the lavender group compared to the betadine group on the $5^{\text {th }}$ day after delivery [15]. The difference between the results might be due to mothers' sitting position. In our study, the mothers were trained to sit in inclined position and use pillows until complete healing in order to prevent edema and sutures opening.

Perineal pain is the most common complaint among women after delivery. Pain causes anxiety and stress, which disrupt the tissues repair process. Thus, perineal pain after delivery can have negative impacts on women's performance in taking care of their infants and family members $[3,6-7]$. Consequently, the present study aimed to compare the three groups with respect to pain intensity. The results showed a significant difference between the olive leaf extract ointment and betadine groups concerning pain intensity on the $10^{\text {th }}$ day after delivery. Tekieh et al. conducted a study on male rats and reported that olive leaf methanolic extract had analgesic effects [18]. Behmanesh et al. (2013) also disclosed that pain intensity was lower in the olive oil group on days 5 and 10 after delivery [14].

Evidence has indicated that oleocanthal in olive oil is an analgesic material, which acts similar to ibuprofen. In fact, oleocanthal suppresses prostaglandins production and exerts its analgesic effects. Up to now, many researchers have estimated the analgesic effects of $50 \mathrm{gr}$ olive oil to be equal to $10 \%$ ibuprofen [14]. Tocopherols are also among the major components of herbal oils, 
including olive oil, which are active as vitamin E. Similar to nonsteroid anti-inflammatory drugs, tocopherol metabolites inhibit cyclooxygenase enzyme, reduce prostaglandins production, and decrease pain. Hence, tocopherols and some fatty acids such as oleic acid can be effective in analgesic effects of olive oil [26]. It should be noted that olive leaf extract rather than olive oil was used in the current study.

One of the limitations of this study was that the participants' individual and genetic variations, economic status, nutritional status, and physical activity that were effective in wound healing could not be controlled. Nevertheless, this was to some extent eliminated by providing similar training and random sampling of the subjects. The small sample size was another limitation of this study.

\section{CONCLUSION}

According to the results of the current study, it seems that olive leaf extract ointment was relatively effective in improvement of episiotomy wound healing. Since using olive leaf extract is a simple, low-cost, and time-saving treatment method, it can be easily used for individuals. The results of this study could be practiced for pregnant women in health centers in order to encourage them to apply healing methods for episiotomy care and reduce the complications of chemical drugs. Yet, further studies with larger sample sizes and longer follow-up periods are recommended to be conducted on the issue.

\section{ACKNOWLEDGEMENT}

This study was extracted from the thesis written by Ms. Sara Sepasi, (proposal No: 94-7472) which was approved by Shiraz University of Medical Sciences. Hereby, the authors would like to thank Ms. A. Keivanshekouh at the Research Improvement Center of Shiraz University of Medical Sciences for improving the use of English in the manuscript.

\section{CONFLICT OF INTERESTS}

The authors report no declarations of interest

\section{REFERENCES}

1. Eghdampour F, Jahdie F, Kheyrkhah M, Taghizade M, Naghizadeh S, Haghani $H$. The effect of aloe vera ointment in wound healing of episiotomy among primiparous women. Iran J Obest Gynecol Infertil 2013;15:25-31.

2. Jahdi F, Kheyrkhah M, Haghani H, Taghizade M, Mehrabi E, Eghdampour F. The effect of aloe vera ointment on the intensity of perineal pain following episiotomy: a randomized blinded clinical trial. J Sabzevar Univ Med Sci 2011;4:243-9.

3. Azhari S, Aradmehr M, Rakhshandeh H, Tara F, Shakeri MT. The effects of Chamomile cream on wound healing of episiotomy in primiparous women. Iran J Obest Gynecol Infertil 2014;93:16-26.

4. Jahdie F, Eghdampour F, Haselie AR, Kheyrkhah M, Hagani H, Abasi Z. The effect of Calendula ointment in wound healing of episiotomy among primiparous women admitted in Lolagar Hospital of Tehran, 2010. J North Khorasan Univ Med Sci 2012;4:124.

5. Khajavi Shojae K, Davati A, Zayeri F. Frequency and side effect of episiotomy in primiparous women: a three-month longitudinal survey. Qom Univ Med Sci J 2009;2:1-4.

6. Golmakani N, Rabiei Motlagh E, Tara F, Asili J, Shakeri MT. The effects of turmeric (Curcuma longa L.) ointment on the healing of episiotomy site in primiparous women. Iran J Obest Gynecol Infertility 2009;4:29-38.

7. Khadivzadeh T, Molkizadeh M, Rakhshandeh H, Khajedaloui M. The impact of Lavender cream on episiotomy pain and wound healing in primiparous women. J Mashhad Sch Nurs Midwifery 2009;1:19-24.
8. Rafiei Z, Jafari SM, Alami M, Khomeiri M. Evaluation of antimicrobial activity of olive leaf extracts by ELISA method. Iran J Med Aromatic Plants 2012;2:280-92

9. Lee $\mathrm{OH}$, Lee BY. Antioxidant and antimicrobial activities of individual and combined phenolic in Olea europaea leaf extract. Bioresour Technol 2010;10:3751-4.

10. Markin D, Duek L, Berdicevsky I. In vitro antimicrobial activity of olive leaves. Mycoses 2003;3-4:132-6.

11. Hill PD. Psychometric properties of the REEDA. J Nurs Midwifery 1990;3:162-5.

12. Shamaeian Razavi N, Bahri Binabaj N, Hoseiny Shahidy L, PourHeidari M. The effect of maternal position on labor pain. J Gonabad Fac Med Sci 2006;2:16-21.

13. Pazndeh F, Savadzadeh S, Mojab F, Alavi Majd H. Effect of chamomile essential oil aromatherapy with episiotomy pain. J Nurs Midwifery Shahid Beheshti Univ Med Sci 2008;62:5-12.

14. Behmanesh F, Aghamohammadi A, Zeinalzadeh M, Khafri S. Effects of olive oil sitz bath on the improvement of perineal injury after delivery. Koomesh 2013;3:309-15.

15. Vakilian K, Attarha M, Bekhradi R, Ghebleh F, Hatami Z, Seraj A. The effect of lavender in care of postpartum episiotomy wounds. J Shahrekord Univ Med Sci 2008;3:63-9.

16. Stedenfeldt M, Pirhonen J, Blix E, Wilsgaard T, Vonen B, Oian P. Episiotomy characteristics and risks for obstetric anal sphincter injuries: a case-control study. Br J Obstet Gynaecol 2012;6:724-30.

17. Khani S, Zare K, Ramezannezhad SE. The frequency of episiotomy and its related factors. Iran J Nurs 2012;74:45-52.

18. Tekieh E, Moghadamkia S, Eidi A, Taghizadfarid R, Ferdosi R, Zaringhalam J. Investigation on the anti-inflammatory and analgesic effects of Olea europaea $L$ methanolic extract on male NMRI mouse. Iran South Med J 2012;1:13-23.

19. Koca U, Suntar I, Akkol EK, Yilmazer D, Alper M. Wound repair potential of Olea europeae L. leaf extracts revealed by in vivo experimental models and comparative evaluation of the extract's antioxidant activity. J Med Food 2011;1-2:140-6.

20. Yu N, Zhai X, Xin C. An experimental study of rabbits' wound repair by amniotic carrier complex membrane containing bFGF and vitamin $\mathrm{C}$ and loaded with BMSCs. ZhongguoXiu Fu Chong Jian WaiKeZaZhi 2008;12:1495-500.

21. Parivar K, Yaghmaei $\mathrm{P}$, Heidari S. In vivo study of the effect of Kombucha on the injured skin of adult NMRI mice strain. Med Sci 2012;4:262-7.

22. Mirazi N, Vatanchiyan M. Evaluation of the effect of Olea europaea $L$ aqueous extract on skin wound healing in adult male mice. Dev Biol J 2010;9:7-14.

23. Mehraein F, Sarbishegi M, Aslani A. Evaluation of the effect of oleuropein on skin wound healing in aged male Balb/c mice. Cell J 2014;1:25-30.

24. Suntar IP, Akkol EK, Baykal T. Assessment of anti-inflammatory and antinociceptive activities of Olea europaea L. J Med Food 2010;2:352-6.

25. Cvjeticanin T, Miljkovic D, Stojanovic I, Dekanski D, StosicGurjicic S. Dried leaf extract of Olea europaea ameliorates inlet directed autoimmunity in mice. Br J Nutr 2010;10:1413-24.

26. Eidi A, Moghadam-kia S, Zarringhalam Moghadam J, Rezazadeh S, Eidi M. Antinociceptive effect of olive oil(Olea europaea L.) on mice. J Arak Univ Med Sci 2011;14:52-9.

\section{How to cite this article}

- Maasumeh Kaviani, Sara Sepasi, Sara Azima, Masoumeh Emamghoreishi, Nasrin Asadi, Sezaneh Haghpanah. The effects of olive leaf extract ointment on pain intensity and early maternal complications in primiparous women. Int J Pharm Pharm Sci 2017;9(7):31-34. 